\title{
O NOVO ENSINO MÉdIO E O PAPEL DA FILOSOFIA COMO ANTIDESPÓTICA: O CURRÍCULO COMO ESTRATÉGIA POLÍTICA
}

\author{
THE NEW HIGH SCHOOL AND THE ROLE OF \\ PHILOSOPHY AS ANTI-DESPOTIC: THE \\ CURRICULUM AS A POLITICAL STRATEGY
}

Aline Francieli Thessing*

REsumo: Neste artigo - a partir dos pressupostos teóricos de Michel Foucault -, busco
compreender como se apresenta discursivamente a implantação do currículo do Novo
Ensino Médio, a partir de propaganda amplamente veiculada em sítio do Ministério
da Educação (MEC). Meu objetivo é perceber o discurso de promoção pelas instâncias
governamentais do referido currículo, de modo a analisá-lo como estratégia política e
de poder. Para tanto, foco minha atenção no discurso que retoma o homem econômico
(FOUCAULT, 2008 [1979]) e, também, busco analisar o apagamento da disciplina de
filosofia dentro do currículo do Novo Ensino Médio, intentando perceber como tal
apagamento se dá em razão de serem, conforme postula Foucault (2010 [1978]), os
filósofos, nas sociedades ocidentais, eminentemente antidéspotas.

Palavras-chave: Análise do Discurso; Novo Ensino Médio; Filosofia.

Aвstract: In this article - based on the theoretical assumptions of Michel Foucault we aim to understand how the implementation of the New High School curriculum is discursively presented through the widely promoted advertising on the website of the Brazilian Ministry of Education (MEC). Our goal is to detect the discourse of promotion deriving from governmental instances about this curriculum to be able to analyze it as a political and power strategy. For this purpose, we focus our attention on the discourse that retakes the economic man (FOUCAULT, 2008 [1979]). Moreover, we also seek to analyze the erasure of the Philosophy discipline within this New High School curriculum. Our attempt to understand such erasure is based on Foucault's (2010 [1978]) postulate that affirms that philosophers in Western societies are eminently opposed to all forms of oppression.

KeYwords: Discourse Analysis; New High School; Philosophy.

\footnotetext{
"Mestre em Linguística, doutoranda também em Linguística pelo Programa de Pós-Graduação em Linguística (PPGL) da Universidade Federal de Santa Catarina (UFSC) na área de concentração em Linguística Aplicada. E-mail de contato: alinethessing@gmail.com.
} 


\section{INTRODUÇÃo}

Em tempos politicamente tão adversos como o que a sociedade contemporânea largamente tem vivido, é amplamente reconhecido o fenômeno do avanço das forças político-ideológicas da direita em todo o mundo, e isso não é diferente em solo nacional. No Brasil, o ideal conservador tem se apresentado de formas variadas, mas uma tem chamado bastante atenção - especialmente aos professores - mais especificamente aqueles que, enquanto profissionais da educação, entendem a especificidade do seu trabalho como a atividade de promoção da formação humana com adjetivação integral - e, assim, dedicam-se à educação das novas mentes -, o chamado obscurantismo beligerante, assumido, neste artigo, a partir do que postula Duarte (2018, p. 139) como fenômeno que se caracteriza pelo avanço dos ideais da direita conservadora no mundo. Para o autor:

Trata-se da difusão de uma atitude de ataque ao conhecimento e à razão, de cultivo de atitudes fortemente agressivas contra tudo aquilo que possa ser considerado ameaçador para posições ideológicas conservadoras e preconceituosas.

Por conseguinte, à guisa de explicação acerca do agenciamento de tal conceito na análise que me proponho a promover neste artigo, importa destacar que tal fenômeno tem ganhado espaço privilegiado nas discussões de currículo que se impuseram desde os primeiros ensaios da Base Nacional Comum Curricular (BNCC - BRASIL, 2017) e tem, ainda, estado bastante presente em todas as discussões que circundam a formulação e implantação do currículo do Novo Ensino Médio. Cumpre assinalar, nesse sentido, as estratégias agenciadas para a ascensão do ideal conservador e, desse modo, especialmente, para o avanço organizado e sistemático do capitalismo - em sua vertente neoliberal, que se faz sentir - não podendo ser diferente, já que a escola reproduz as forças postas na sociedade vigente - nas políticas educacionais atuais, dentre elas, a que tomo como foco de análise, que é a implantação do currículo do intitulado Novo Ensino Médio. Nesse sentido, proponho-me a uma tentativa de análise do discurso de divulgação levada a termo nas instâncias midiáticas do Governo Federal, mais especificamente na página do site do Novo Ensino Médio do Ministério da Educação (MEC). Para tanto, ancoro-me na teoria de análise do discurso foucaultiana, de modo a contemplar com maior atenção os pressupostos propostos pelo autor francês em relação ao avanço e à eficácia do programa neoliberal que se identifica tão logo nas propostas de educação. Esse trabalho se dará, como já referenciado, a partir da análise de materiais divulgados amplamente pelo MEC em sítio online próprio para a promoção e lançamento do currículo do Novo Ensino Médio. Dessa forma, a análise só será possível em razão das discussões feitas a partir do amplo acervo teórico do autor francês sobre a governabilidade, o neoliberalismo e o despotismo. 


\section{O homo oeconomicus E o CURRículo do Novo Ensino MÉdio}

Em O Nascimento da Biopolítica (2008 [1979]), Michel Foucault apresenta um empenhado e acurado modo de pensar sobre a lógica neoliberal-a partir do neoliberalismo norte-americano. O autor faz um percurso histórico acerca do fenômeno econômico em questão - que não será meu foco de atenção neste texto -, mas que importa considerar, uma vez que tais políticas econômicas são determinantes no que se refere às políticas educacionais atuais submetidas ao liberalismo em sua vertente mais acentuada. Para Foucault, o liberalismo norte-americano parte de uma política keynesiana, desenvolvida por Roosevelt, passa pelos tratados de guerra e culmina nos programas sociais com intervencionismo do Estado, dentre eles, aqueles relacionados à educação. Nesse sentido, ao pensar a lógica neoliberal norte-americana e as profundas influências desta na Europa e em todo o mundo, o autor retoma e ratifica o homem-máquina, o homem neoliberal que precisa produzir salário, não porque compreende que vende sua força de trabalho como mercadoria, mas porque é homem econômico, que está disposto a aceitar a realidade tal como lhe é apresentada a cada tempo e espaço. Para o autor francês, o neoliberalismo traz de volta o homo oeconomicus - dos estudos econômicos do século XVI e XVII - mas agora, segundo Foucault (2008 [1979], p. 311), ressignificado:

o homo oeconomicus, aqui, não é em absoluto um parceiro da troca. O homo oeconomicus é um empresário, e um empresário de si mesmo. Essa coisa é tão verdadeira que, praticamente, o objeto de todas as análises que fazem os neoliberais será substituir, a cada instante, o homo oeconomicus parceiro da troca por um homo oeconomicus empresário de si mesmo, sendo ele próprio seu capital, sendo para si mesmo seu produtor, sendo para si mesmo a fonte de [sua] renda.

Essa análise a partir do ideário foucaultiano se dá como tentativa de compreensão das reverberações discursivas apresentadas na página oficial do MEC sobre o Novo Ensino Médio e seu suporte curricular, a BNCC (BRASIL, 2017). É, pois, no sentido do enunciado que se constrói em favor das relações de poder que se quer estabelecer que se funda o Currículo do intitulado Novo Ensino Médio. Assim, o discurso que se forma a partir dos meios autorizados pelo Governo Federal, como o sítio online do Novo Ensino Médio do MEC, coloca em curso não apenas a promoção de um currículo educacional, mas um modo de governar pautado no ideal neoliberal. Ainda por esse viés, já na página de entrada da proposta do Novo Ensino Médio no Portal do MEC, aparecem materializadas as manifestações enunciativas que retomam o homem econômico neoliberal de que fala Foucault (2008 [1979]). Esse homem, que é agente de seu sucesso e de sua miséria, é empresário de si, sendo a ele facultadas todas as escolhas e, consequentemente, todas as responsabilidades, já que tais escolhas são pretensamente enunciadas como suas. Assim, o discurso se manifesta a partir da exposição, em destaque, do papel protagonista dos sujeitos no processo curricular. Nesse sentido, o sítio do Novo Ensino 
Médio do MEC destaca que os estudantes (agentes do próprio processo pedagógico) poderão escolher, a partir de seus interesses pessoais, o que cursarão do currículo:

Além das aprendizagens comuns e obrigatórias, definidas pela Base Nacional Comum Curricular, os estudantes poderão escolher se aprofundar naquilo que mais relaciona com seus interesses e talentos. São os itinerários formativos, relacionados às áreas do conhecimento (Matemática, Linguagens, Ciências Humanas e Ciências da Natureza) e com a formação técnica e profissional (BRASIL, 2019).

Ressalto que, nessa manifestação discursiva - que se confirma em caixa-alta e letras garrafais em uma página colorida -, estão implicadas não apenas nuances de um novo formato de currículo, mas de uma estratégia de poder, de um estilo de governabilidade. Justamente por isso, propomo-nos a uma análise do discurso que se fomenta pelo próprio Governo Federal, em sua vertente amplamente neoliberal - a partir do discurso que se realiza nas mídias autorizadas pela esfera federal, nas quais os sujeitos governados são convidados - por meio do programa de organização curricular do Novo Ensino Médio - a fazer parte do jogo político. Esses sujeitos que são agenciados pelo projeto de poder vigente são, para nós, o homo oeconomicus, retomado e ressignificado na obra de Foucault, mais precisamente em Nascimento da Biopolítica (2008).

\section{O CURRÍ́culo COMO ESTRATÉGIA DE PODER}

Isso posto, passo a me valer da perspectiva de análise econômica a partir do liberalismo norte-americano proposto por Foucault (2008 [1979], p. 301), quando o autor afirma que "o liberalismo, nos Estados Unidos, é toda uma maneira de ser e de pensar. É um tipo de relação entre governantes e governados, muito mais que uma técnica dos governantes em relação aos governados”. O currículo assumido como estratégia política se conforma, assim, como estratégia de poder. Desse modo, prossegue o que se enuncia ainda na página do novo currículo do MEC:

O Novo Ensino Médio torna obrigatório que o projeto de vida dos estudantes seja desenvolvido em todas as escolas. Ou seja, você desenvolverá habilidades como ser cooperativo, saber defender suas ideias, entender as tecnologias, compreender, respeitar e analisar o mundo ao seu redor. Além disso, terá apoio para escolher os caminhos que irá seguir no próprio ensino médio e em seu futuro profissional (BRASIL, 2019 - grifos meus).

Mais uma vez, o discurso que se anuncia coloca os sujeitos como profundamente responsáveis - agentes únicos - no desenvolvimento de seu percurso formativo e, mais do que isso, como se fossem, desse modo e não de outro, profundamente respeitados no que se refere ao desenvolvimento de seus ideais e projetos de vida, uma vez que escolherão seu percurso 
curricular e de vida. Tal discurso é por mim analisado como tendo profundo comprometimento com o ideal neoliberal, e esta análise se dá a partir dos pressupostos de Foucault sobre a economia norte-americana, já que a análise econômica - como o próprio autor reitera em sua obra - pode ser aplicável a condutas que extrapolem as do mercado, visto que "é uma espécie de reivindicação global” (FOUCAULT, 2008 [1979], p. 301). Nesse sentido, esse projeto de vida dos estudantes, que será desenvolvido a partir da implantação do currículo do Novo Ensino Médio, não está dissociado - a partir do que se enuncia do sítio do referido currículo - de um projeto profissional desse estudante, o que corrobora com uma formação educacional que visa à formação de capital humano, e significa "formar, portanto, essas espécies de competência-máquina que vão produzir renda, ou melhor, que vão ser remuneradas por renda”. Para Foucault (2008 [1979], p.315), essa formação de capital humano não pode se dar senão por investimentos educacionais, mas tais investimentos, assumidos como meta para os neoliberais, ultrapassam e muito o mero aprendizado escolar, uma vez que a formação de capital humano depende de condições materiais diversas, como tempo dedicado à criação dos filhos, o repertório sociocultural dos pais, que quanto mais vasto, mais contribuirá para a criação de "bom" capital humano, além de investimentos em saúde, mobilidade, etc. No entanto, tal investimento é certo que se dá de modo muito diverso em contextos sociais de países de primeiro e de terceiro mundo, por exemplo, e isso é facilmente verificável no âmbito nacional, como procuro mostrar na análise da proposta do Novo Ensino Médio. Nessa esteira, o currículo do Novo Ensino Médio é remetido aqui como um dos investimentos educacionais neoliberais. Dessa forma, importa considerar que as ações promovidas pelas mudanças efetivas no currículo educacional reverberam na formação do capital humano apresentado e discutido por Foucault (2008) e contemplam os interesses políticos e de poder daqueles que governam.

\section{A disciplina DE FILOSOFIA E SEU PAPEL ANTIDESPótico}

Dito isso, importa destacar algo bastante significativo no currículo do Novo Ensino Médio. Tal currículo propõe - a partir da escolha dos estudantes agentes de seu percurso formativo balizado pelo interesse individual - a diluição de áreas do conhecimento como a filosofia. Como sinalizado anteriormente, essa é uma estratégia bastante condizente com os avanços das forças neoliberais conservadoras, como as vigentes atualmente. Assim, tal negação/diluição se dá a partir do enunciado que possibilita a "escolha pelo estudante dos caminhos que irá seguir no próprio ensino médio e em seu futuro pessoal e profissional" (BRASIL 2019 - grifos meus), uma vez que currículos pautados exclusivamente em uma formação técnica não contarão com disciplinas das áreas das ciências humanas, como a filosofia, pois efetivamente apenas o ensino de matemática e língua portuguesa é obrigatório no novo currículo, visto que as demais disciplinas "(Biologia, Física, Química, Sociologia, História, Geografia, Filosofia, Artes e Educação Física) serão diluídas em grandes áreas - Ciências da Natureza 
e suas tecnologias e Ciências Humanas e Sociais Aplicadas" (LINDBERG, 2019), e podem ou não - a depender da escolha dos alunos - fazer parte do percurso curricular. Nesse sentido, a premissa que é assumida neste artigo é a de que isso se conforma de tal modo em razão de a filosofia ser não apenas uma disciplina a ser ministrada nos interiores escolares, mas, mais do que isso, uma estratégia de contrapoder, uma vez que pode promover a crítica ao poder dominante, podendo apurar a crítica de tal modo que esse poder vigente se torne despótico. Corrobora com essa análise a discussão promovida por Foucault (2010 [1978]), em que o autor apresenta o filósofo nas sociedades ocidentais como, eminentemente, um antidéspota, uma vez que ele - o filósofo - atua como aquele capaz de pôr limites ao excesso de poder. Para o autor francês, o “filósofo foi 'antidéspota' definindo, ele próprio, o sistema das leis segundo as quais, em uma cidade, o poder deveria ser exercido, definindo os limites legais dentro dos quais ele podia ser exercido sem perigo" (FOUCAULT, 2010 [1978], p. 41). Nesse sentido, ainda no sítio principal do Novo Ensino Médio, na página do MEC, na seção de perguntas e respostas, uma das perguntas enunciadas refere-se à permanência da filosofia nos currículos do Ensino Médio no novo formato. O que se enuncia como resposta imediata é que a disciplina não sairá do currículo, permanecendo como obrigatória nessa etapa da educação escolar. No entanto, o que se destaca no enunciado proferido é que o próprio discurso se constrói a partir daquele sujeito homem-máquina - responsável pelas escolhas na sua formação, uma vez que tal obrigatoriedade não se dará ao longo dos três anos do percurso escolar referido, o que poderia efetivamente contribuir para que fosse conferido um senso crítico mais apurado aos estudantes. Destaco o que se evidencia na página sobre o Novo Ensino Médio do MEC:

A LDB inclui, no ensino médio, obrigatoriamente, estudos e práticas de educação física, arte, sociologia e filosofia (Art. 35-A, $\$ 2^{\circ}$ ). Já o ensino de língua portuguesa e matemática será obrigatório nos três anos do ensino médio, assegurada às comunidades indígenas, também, a utilização das respectivas línguas maternas ( $\left.\mathrm{LDB}, \mathrm{Art} .35-\mathrm{A}, \$ 3^{\circ}\right)$, independente da(s) área(s) de aprofundamento que o estudante escolher em seu itinerário formativo (BRASIL, 2019, grifos meus).

Novamente, enveredo-me por uma análise em que se perceba a reverberação do viés neoliberal, de modo que, por se tratar de um campo do conhecimento profundamente implicado com as relações de poder, a filosofia pode apresentar-se como um contrapoder, uma vez que assume a tarefa de "intensificar as lutas que se desenrolam em torno do poder, as estratégias dos adversários no interior das relações de poder, as táticas utilizadas, os focos de resistência" (FOUCAULT, 2004, p. 43), podendo, assim, permitir aos sujeitos questionar ou não se articular tão fortemente e necessariamente ao neoliberalismo vigente. Assim, a diluição - para não dizer retirada - da disciplina da filosofia - para aqueles que fizerem essa "escolha", como se concebe nos dizeres constantes, os quais todos são convidados a compartilhar, seja na página oficial do currículo do Novo Ensino Médio, seja nas peças publicitárias, 
manifesta-se, pelo que pode ser conferido, a partir de uma análise discursiva com base no pensamento de Michel Foucault, como uma estratégia articulada de manutenção do poder e da ordem vigente, a capitalista neoliberal.

Cumpre, nesse sentido, ressaltar o papel profundamente antidespótico da filosofia. $\mathrm{O}$ que se materializa no discurso pró-autonomia dos sujeitos em relação à escolha do currículo, mesmo que essa escolha culmine no esvaziamento da disciplina da filosofia, são os profundos interesses nas relações de manutenção de poder por uma classe dominante, participante da governabilidade. A partir do que se estabelece na organização curricular da BNCC (BRASIL, 2017) que será posta em prática no dito Novo Ensino Médio, o que se vislumbra é um profundo enraizamento ao homo oeconomicus e seu papel de homem empresário, responsável por sua miséria e seu sucesso e, mais ainda, a filosofia como aquela que pode reagir, se assumir seu papel de Estado filosófico, ao despotismo que se levanta com o avanço das forças neoliberais e de extrema direita.

Não importa tanto o conteúdo a ser manifestado pelo currículo, mas as estratégias de poder que se manifestam nos enunciados. Desse modo, assume-se, então, o que Foucault nos diz sobre o enunciado, uma vez que, no currículo, não é o conteúdo, como já reiterado diversas vezes ao longo deste artigo, que incomoda, mas uma estratégia de poder que é agenciada. Para o filósofo francês, o "enunciado circula, serve, se esquiva, permite ou impede a realização de um desejo, é dócil ou rebelde a interesses, entra na ordem das contestações e das lutas, torna-se tema de apropriação ou de rivalidade" (FOUCAULT, 2008 [1979], p. 21).

A filosofia, portanto, como aquela capaz de tornar visível o que ninguém vê - um fazer aparecer de algo que está tão próximo ao sujeito que este não o consegue perceber, pois tão imediato que é, lhe escapa -, torna-se um perigo para aqueles que detêm o poder. Uma formação pautada não no âmbito pragmático apenas, como quer a BNCC (BRASIL, 2017), e que supere o indivíduo enquanto capital humano - no âmbito de competência-máquina, pode, de fato, formar sujeitos que possam competir com o poder. Nesse sentido, a filosofia cumpriria seu papel antidespótico.

\section{Conclusão}

Nesses termos, o que se buscou até aqui foi uma análise - não pormenorizada dado o espaço limitado de um artigo, mas nem por isso descuidada - do discurso apresentado no sítio oficial do MEC em referência à implantação em território nacional do currículo do Novo Ensino Médio. Nesse sentido é que necessariamente retomo o conceito aqui antes apresentado brevemente de obscurantismo beligerante (DUARTE, 2018), assumido como manifestação agressiva a tudo aquilo que possa se demonstrar ameaçador para posições ideológicas conservadoras, o que se justifica na breve análise do discurso que se forma em favor da implantação de um currículo que se apresenta não como mera estratégia educacional, mas como estratégia de poder, análise esta que tentei realizar nestas páginas. 
Nesse sentido, a partir dos pressupostos da análise do discurso do filósofo Michel Foucault é que busquei apresentar o currículo do Novo Ensino Médio como uma retomada do homem econômico norte-americano - empresário de seu próprio sucesso e, por isso, essencialmente neoliberal -, procurando, então, demonstrar, ao longo da construção discursiva apresentada pelos órgãos oficiais de divulgação do referido currículo - sítio da internet em forma de propaganda veiculada pelo $\mathrm{MEC}$-, como o currículo se apresenta não apenas como estratégia educacional, mas como estratégia política e de poder. Assim, empenhei-me em compreender - uma vez que o currículo é assumido como tal - o papel da filosofia como antidespótica (FOUCAULT, 2010 [1978]) e os profundos interesses que marcam seu apagamento no currículo do Novo Ensino Médio.

Nesse sentido, por se tratar de uma estratégia de poder e não apenas da composição do currículo de disciplinas para uma determinada etapa da formação escolar é que me propus a um esforço em - a partir de uma proposição analítica (FOUCAULT, 1988) - dizer que o discurso que permeia a proposta do Novo Ensino Médio apenas faz ressoar o projeto em curso das forças políticas e ideológicas da reprodução do capital, do neoliberalismo em sua face conservadora, que avança a passos largos em nossa sociedade.

\section{REFERÊNCIAS}

BRASIL. Ministério da Educação. Secretaria da Educação Básica. Base nacional comum curricular. Brasília, DF, 2017. Disponível em: http://basenacionalcomum.mec.gov.br. Acesso em: 30 ago. 2019.

BRASIL. Ministério da Educação. Novo Ensino Médio. Disponível em: http://novoensinomedio. mec.gov.br. Acesso em: 28 ago. 2019.

DUARTE, Newton. Rev. Espaço do Currículo (online). João Pessoa, v. 11, n. 2, p. 139-145, mai./ ago. 2018.

FOUCAULT, Michel. A Arqueologia do Saber. Rio de Janeiro: Forense, 1988.

FOUCAULT, Michel. “A Filosofia Analítica da Política”. Ditos e Escritos. v. V - Ética, Sexualidade, Política. Rio de Janeiro: Forense Universitária, 2004.

FOUCAULT, Michel. Nascimento da Biopolítica. São Paulo: Martins Fontes, 2008 [1979].

FOUCAULT, Michel. O Governo de Si e dos Outros. São Paulo: Martins Fontes, 2010 [1978].

LINDBERG, Christian. O ensino de Filosofia e a reforma educacional: o que fazer? ANPOF. 5 abr. 2019. Disponível em: https://anpof.org/portal/index.php/en/comunidade/coluna-anpof/2052-oensino-de-filosofia-e-a-reforma-educacional-o-que-fazer. Acesso em: 5 maio 2020.

Recebido para publicação em: 11 maio 2020. Aceito para publicação em: 9 ago. 2020. 